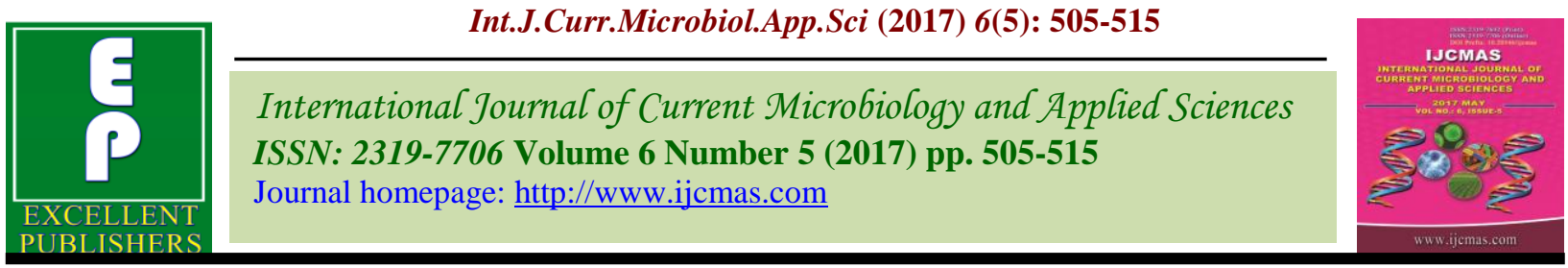

Original Research Article https://doi.org/10.20546/ijcmas.2017.605.059

\title{
Study of the Prevalence of Risk Behaviour for HIV among Tuberculosis Patients
}

\author{
Ankur Gupta ${ }^{1}$, Priyanka Soni Gupta ${ }^{2} *$ and Rakesh Chandra Gupta ${ }^{3}$ \\ ${ }^{1}$ Senior Medical Officer, ${ }^{3}$ Former Principal and and Head of Department, \\ Department of TB \& Respiratory diseases, India \\ ${ }^{2}$ Assistant Professor, Department of Microbiology, Jawahar Lal Nehru Medical College and \\ Associated group of Hospitals, Ajmer, Rajasthan, India \\ *Corresponding author
}

A B S T R A C T

The association between tuberculosis and HIV presents an immediate and grave public health and socioeconomic threat, particularly in the developing world. The interaction of TB with HIV is two-folded, with TB being the leading cause of death among HIV infected, and HIV infection being the most potent risk factor for a latent TB infection to convert to

\section{Keywords}

HIV,

TB, Tuberculosis \&

Respiratory diseases

(NITRD),

Risk Factors.

\section{Article Info}

Accepted:

04 April 2017

Available Online:

10 May 2017 active disease. The study was conducted on patients diagnosed with pulmonary and extra pulmonary tuberculosis, who were admitted in the wards of National Institute of Tuberculosis \& Respiratory diseases (NITRD), New Delhi. 397 Patients were enrolled for the study after informed consent from July 2009 to March 2011. Each patient was studied for risk behaviour using modified national sexual health survey questionnaire. 397 cases of pulmonary tuberculosis were studied, out of which 24 were found to be HIV sero positive. Most of the patients were between early twenties to late forties. Promiscuous sexual behavior was found in $87.5 \%$ HIV seropositive pulmonary TB patients and thus emerged as a very important risk factor. The most important risk behaviours associated with HIV seropositivity were found to be occupation (high in unemployed, labourer, truck drivers), marital status, multiple sex partners, homosexual behavior, condom use, presence of sexually transmitted diseases, visit to commercial sex workers \& use of recreational substances like alcohol before sex ( $\mathrm{p}$ value<0.0001). Condom use and substance use risk reduction need to be considered as HIV-prevention measures when planning HIVprevention programmes for TB patients. Other parameters which did not show statistical significance, although described as high risk factors in some previous studies, were age and $\operatorname{sex}(\mathrm{p}=0.06)$, religion $(\mathrm{p}=0.173)$, educational status $(\mathrm{p}=0.445)$, migration $(\mathrm{p}=0.126)$ and low socioeconomic status $(\mathrm{p}=0.392)$.

\section{Introduction}

Tuberculosis (TB) has existed for millennia and remains a major global health problem. It causes ill-health in millions of people each year and in 2015 was one of the top 10 causes of death worldwide, ranking above HIV/AIDS as one of the leading causes of death from an infectious disease (World Health Organisation, 2016). The association between tuberculosis and HIV presents an immediate and grave public health and socioeconomic threat, particularly in the developing world. Co-infection of these two 
diseases has been considered to be a major obstacle for the global efforts in reaching the goals for the prevention of HIV and TB infections (Xu et al., 2014). HIV infection is a risk factor predisposing to Mycobacterium tuberculosis infection and progression to active disease. Mycobacterium tuberculosis and HIV act in synergy, accelerating the decline of immunological functions and leading to subsequent death of patient if untreated (Pawlowski et al., 2012). HIV infection worsens the tuberculosis situation by increasing reactivation of latent tuberculosis in dually infected persons as well as by favoring rapid progression of new infections in the HIV-infected.

TB is often the first disease that an HIVinfected person contracts. An HIV-infected person is six times (50-60 per cent lifetime risk) more likely to develop TB disease once infected as compared to 10 per cent lifetime risk in an HIV - negative person (Talzek, 1997; Agarwal et al., 2005). The impact of the two epidemics on resource-poor countries has ominous social and medical implications, and the already overstretched health services now have to face a tremendously increasing tuberculosis problem.

The interaction of TB with HIV is two-folded, with TB being the leading cause of death among HIV infected, and HIV infection being the most potent risk factor for a latent $\mathrm{TB}$ infection to convert to active disease.

Global burden in 2015 -16 (World Health Organisation, 2016; TB-HIV Factsheet, 2016)

In 2015, there were an estimated 10.4 million new (incident) TB cases worldwide.

Six countries accounted for $60 \%$ of the new cases of TB: India, Indonesia, China, Nigeria, Pakistan and South Africa.
In India, the estimate of incidence (new TB cases per year) is 2.8 million cases in 2015 (The updated estimates for India should be considered interim in nature, pending a more definitive assessment that will follow completion of a national $\mathrm{TB}$ prevalence survey, which is scheduled to start in 2017).

In 2015, 1.1 (940 000-1.3 million) million people died from HIV-related causes globally. There were approximately 36.7 (34.0-39.8) million people living with HIV at the end of 2015 with 2.1 (1.8-2.4) million people becoming newly infected with HIV in 2015 globally.

People living with HIV accounted for 1.2 million $(11 \%)$ of all new TB cases worldwide. India has been reported to be in the $0-4.9 \%$ zone of HIV prevalence in new TB cases.

There were an estimated 1.4 million TB deaths in 2015, and an additional 0.4 million deaths resulting from $\mathrm{TB}$ disease among people living with HIV. TB is the leading cause of death among people living with HIV390,000 died from HIV associated TB in 2015 .

In 2015, 6.4 million people with $\mathrm{TB}$ were notified to national TB programmes (NTPs) and reported to WHO. The number of new and relapse TB cases notified and the notification rate per 100000 population increased globally in 2013-2015, mostly explained by a $34 \%$ increase in notifications in India.

Globally in 2015, 55\% of notified TB patients (3.4 million) had a documented HIV test result, an 18-fold increase in testing coverage since 2004.

In total, $231637(10 \%)$ of the almost 2.3 million people who were newly enrolled in HIV care in 2015 were notified as TB cases during the same year. 
People living with HIV are 19 times (17-22) more likely to fall ill with TB than those without HIV. People living with HIV face the threat of drug-resistant TB.

Objectives of surveillance of HIV among tuberculosis patients (Maher et al., 2002; World Health Organization, 2002)

To inform the targeting of resources and the planning of activities for people with HIV and $\mathrm{TB}$ and for monitoring the effectiveness of these activities.

To increase political, professional and civil society awareness of the situation.

To assess the need for collaboration between HIV/AIDS and TB programmes on formulation and implementation of a joint TB/HIV strategy.

To provide information on the HIV/AIDS epidemic and its impact on TB patients.

To quantify the need for providing ART to TB patients. To access the impact of the HIV epidemic on the TB situation.

To monitor the effectiveness of joint strategies aimed at reducing the TB/HIV burden

Globally, HIV is threatening the control of TB. Treatment of co-infection with HIV and TB requires commitment and a focused approach. Appropriate use of antiretroviral drugs to treat HIV infection and ensuring high levels of coverage and compliance is required to prevent TB by preserving immunity. The DOTS strategy is very useful to ensure cure of TB in patients with HIV infection and AIDS. Coordination between the RNTCP and the AIDS control measures is required for effective management of these patients (Maher et al., 2002).
Against this background, the present study was aimed at determining the prevalence and associated risk factors of HIV infection among patients with pulmonary tuberculosis (PTB).

\section{Materials and Methods}

\section{Study design}

The study was a descriptive and observational type of study conducted on patients diagnosed with pulmonary and extra pulmonary tuberculosis and on anti tubercular treatment. Each patient was studied for risk behavior using modified national sexual health survey questionnaire.

Study population: Patients were selected from those who were admitted in the wards of National Institute of Tuberculosis \& Respiratory diseases (NITRD), New Delhi during the period, starting from July 2009 to March 2011. Informed consent from the patient was taken for the study. Full confidentiality was maintained with regard to the patient.

Sample size: 397 patients were taken in the study.

\section{Inclusion criteria}

Patients diagnosed with pulmonary tuberculosis.

Patient should be adult, 18 years or more.

\section{Exclusion criteria}

A patient who refuses to consent.

Severely ill patients who are unable to understand the questions.

\section{Methods}

A validated questionnaire was used for the study with which patient's basic information like age, sex, occupation, residence, etc was 
be recorded. Detailed history about risk behaviors for HIV, for example, risky sexual practices, injectable drug use/abuse, transfusion history, and the like was recorded. A detailed assessment of sexual activities was conducted with each of the respondent, in addition to demographic, geographic, and HIV/STD risk characteristics.

\section{Statistical analysis}

Data was collected by the use of questionnaire (Annexure) in Microsoft excel sheet. Data was analyzed using SPSS software for statistical analysis and Pearson Chi Square test was applied to find the significant associations.

\section{Results and Discussion}

This study was conducted on patients diagnosed with pulmonary tuberculosis, who were admitted in the wards of National Institute of Tuberculosis \& Respiratory diseases (NITRD), New Delhi. This study was approved by ethical and research committee. Patients with the diagnosis of pulmonary tuberculosis were enrolled for the study after informed consent from July 2009 to March 2011. 397 patients were enrolled in the study out of which, 24 were found to sero positive. The prevalence of HIV seropositivity in our study is $6.05 \%$.

HIV continues to be a major global public health issue, having claimed more than 35 million lives so far. The harmful collaboration between the HIV and tuberculosis epidemics has added dramatically to the suffering and death caused by each disease alone. The interaction between TB and HIV is twofolded, with TB being the leading cause of death among HIV infected, and HIV infection being the most potent risk factor for a latent TB infection to convert to active disease. This is critical to the success of HIV/TB integrated interventions.
The study included a total of 397 patients diagnosed with pulmonary tuberculosis, admitted in the wards of National Institute of Tuberculosis \& Respiratory diseases (NITRD), New Delhi from July 2009 to March 2011. 24 patients were found to be sero positive for HIV. The prevalence of HIV seropositivity in our study is $6.05 \%$.

\section{Age \& Sex Distribution}

The patients enrolled were in 2nd to 5th decade of their life. Most of the patients were between early twenties to late forties. 50\% were from the age group of 26-63 years and 36-40 years combined.83\% of HIV positive patients were less than 40 years of age (Table $1,2)$. There was no significant association between age distribution and HIV serostatus in this study. With respect to sex distribution among study group, 46 (11.6\%) were females and $351(88.4 \%)$ were males. All cases of HIV positive were males. Sex distribution among patients was not found to be statistically significant. Thus age and sex were not found to be a risk factor for HIV infection in tuberculosis patients.

\section{Religion Distribution}

In Present study $322(81 \%)$ belonged to Hindu community and $75(18.8 \%)$ were to Muslims community. Among Hindu, 22 $(6.83 \%)$ were HIV seropositive while among Muslim population $2(2.67 \%)$ were HIV seropositive (Table 3). There was no significant association between religion and HIV sero status. Thus religion was not found to be a risk factor for HIV infection in tuberculosis patients. Tabot (2002) and Dandona (2008) suggested that male circumcision is associated with low HIV seroprevalence and may be considered as a risk factor for HIV disease.

Education Status: In Present study, 135 (34\%) were illiterate, 171 (43.1\%) had left their studies even before completing primary 
school. Both these groups constitute more than $75 \%$ of the patients. HIV seropositivity among these two groups is $91.6 \%$ (9 in illiterate group and 13 in upto 5 th standard out of 24 HIV seropositives) (Table 4). However the association between education and HIV seropositivity was not found to be significant in accordance with study done by Oladeinde et al., (2014). In contrast to this, a significant association has been reported in various other studies conducted from all over the world (Talbot et al., 2002; Dandona et al., 2008; Jain et al., 2000; Ramachandran et al., 2011; Srikantiah et al., 2007).

\section{Occupational Status}

In Present study, 34 (8.7\%) were unemployed at the time of study as they are daily wagers and no fixed jobs. 164 (41.3\%) were labourers and 8 were truck drivers. 6 out of 8 truck drivers in this study were found to be HIV positive (Table 5). The association between occupation and HIV status was found to be significant which is also echoed in other studies (Pandey et al., 2008) in contrast to non association reported by Oladeinde et al., (2014).

\section{Migration}

In this study, 141 patients $(35.5 \%)$ were migrants and 256 (64.5\%) were non migrants. Most of the migrant population was found to be laborers coming in search of better job opportunities (Table 6). However the association between migration and HIV status was not significant. Tabot (2002) found that those who were HIV positive reported more moves from their homes mostly due to occupational reasons. They also observed that separation from a regular sex partner and infidelity during separation are common, and that longer duration of separation is associated with HIV infection.

Income: In Present study majority of the patients $(84 \%)$, had monthly income of less than 5000 rupees (Table 7). The association of economic status with respect to HIV status was not significant. Thus income was not found to be a risk factor for HIV infection in tuberculosis patients.

\section{Marital Status}

In this study, $286(72 \%)$ were married and 83 (20.9\%) were unmarried. 13(54.2\%) among married group and 7 (27.2) among unmarried group were HIV positive (Table 8). The association between marital status and HIV status was significant in our study. Marital status was found to be a risk factor for HIV infection in tuberculosis patients. Similar results of significant association with marital status has been echoed in various other studies (Talbot et al., 2002; Dandona et al., 2008; Jain et al., 2000; Ramachandran et al., 2011; Srikantiah et al., 2007) in contrast to non association reported by Oladeinde et al., (2014).

\section{Sexual Practices and Behaviour}

In Present study, $337 \quad(84.8 \%)$ were heterosexual and 13 were bisexual $(3.2 \%)$. Among heterosexual group, 17(5\%) were seropositive and among bisexual 7(53.8\%) were seropositive (Table 9). There is significant association between sexual orientation and seropositivity and risk behavior. The association between sexual behavior and practices among the study group was significant. Promiscuous sexual behavior is associated in 18 patients (75\%) where as 3 (12.5\%) had monogamous relationships. 376 patients declined to answer the question (Table 10). Promiscuous behavior in $87.5 \%$ HIV seropositive pulmonary TB patients thus emerged as very important risk factors among TB patients. The association between number of sex partners with respect to HIV status was significant. 14 patients accepted to have had visited a CSW in past 1 year and all were 
seropositive (Table 11). 10 (2.6\%) out of 383 respondents who denied such risk behavior were seropositive, thereby suggesting strong association. Out of 350 patients, $302(86.2 \%)$ had no history of anal intercourse, 17 patients have history of anal intercourse and out of there 7 patients were HIV seropositive (Table 12). The association between anal sex with respect to HIV status was significant. With respect to the responses about condom use, it was found that all the seropositive patients had not used condoms regularly. Out of 239 (65.2\%),who had not used condoms (9.3\%) were seropositive and out of $138(34.8 \%)$ who used condoms, none was found to be seropositive (Table 13). In this study, the association between condom use and HIV seropositivity was significant. Thus sexual orientation (homosexual behavior), sexual behavior (multiple sex partners \& visit to CSW), sexual practices (anal sex) and condom use were found to be a risk factor for HIV infection in tuberculosis patients in our study. A strong statistical association has also been reported in a large number of studies from all over the world (Talbot et al., 2002; Dandona et al., 2008; Jain et al., 2000; Ramachandran et al., 2011; Srikantiah et al., 2007; Thomas et al., 2009; HIV risk behavior among public PHC patients with TB in South Africa, 2013).

Table.1 Age distribution ( $\mathrm{p}=0.616$, Pearson Chi-Square Test)

\begin{tabular}{|c|c|c|c|}
\hline \multirow{2}{*}{ Age (in years) } & \multicolumn{2}{|c|}{ HIV test result } & \multirow{2}{*}{ Total (\%) } \\
\cline { 2 - 3 } & Positive (\%) & Negative (\%) & $73(18.4)$ \\
\hline$<25$ & $5(20.8)$ & $68(18.2)$ & $83(20.9)$ \\
\hline $26-30$ & $6(25)$ & $77(20.6)$ & $61(15.4)$ \\
\hline $31-35$ & $3(12.5)$ & $58(15.5)$ & $62(15.6)$ \\
\hline $36-40$ & $6(25)$ & $56(15.1)$ & $47(11.8)$ \\
\hline $41-45$ & $1(4.2)$ & $46(12.3)$ & $71(17.9)$ \\
\hline$>45$ & $3(12.5)$ & $68(18.2)$ & 397 \\
\hline Total & 24 & 373 & \\
\hline
\end{tabular}

Table.2 Sex distribution ( $\mathrm{p}=0.067$, Pearson Chi-Square Test)

\begin{tabular}{|c|c|c|c|}
\hline \multirow{2}{*}{ Gender } & \multicolumn{2}{|c|}{ HIV Test result } & \multirow{2}{*}{ Total (\%) } \\
\cline { 2 - 3 } & Positive $(\%)$ & Negative $(\%)$ & $351(88.4)$ \\
\hline Male & $24(100)$ & $327(87.7)$ & $46(11.6)$ \\
\hline Female & $0(0)$ & $46(12.3)$ & 397 \\
\hline Total & 24 & 373 & \\
\hline
\end{tabular}

Table.3 Religion distribution ( $\mathrm{p}=0.173$, Pearson Chi-Square Test)

\begin{tabular}{|c|c|c|c|}
\hline \multirow{2}{*}{ Religion } & \multicolumn{2}{|c|}{ HIV Test Result } & \multirow{2}{*}{ Total (\%) } \\
\cline { 2 - 3 } & Positive (\%) & Negative (\%) & $322(81.1)$ \\
\hline Hindu & $22(91.7)$ & $300(80.4)$ & $75(18.9)$ \\
\hline Muslim & $2(8.3)$ & $73(19.6)$ & 397 \\
\hline Total & 24 & 373 & \\
\hline
\end{tabular}


Table.4 Educational status ( $\mathrm{p}$ value $=0.445$, Pearson Chi-Square Test)

\begin{tabular}{|c|c|c|c|}
\hline \multirow{2}{*}{$\begin{array}{c}\text { Educational } \\
\text { status }\end{array}$} & \multicolumn{2}{|c|}{ HIV test result } & \multirow{2}{*}{ Total (\%) } \\
\cline { 2 - 3 } & Positive (\%) & Negative (\%) & \\
\hline Illiterate & $9(37.5)$ & $126(33.8)$ & $135(34.0)$ \\
\hline Upto 5 th std & $13(54.2)$ & $158(42.4)$ & $171(43.1)$ \\
\hline $6-8$ std & $2(8.3)$ & $52(13.9)$ & $54(13.6)$ \\
\hline $8-10$ & 0 & $36(9.7)$ & $36(9.1)$ \\
\hline $11-12$ & 0 & $1(0.3)$ & $1(0.3)$ \\
\hline graduate & 0 & 0 & 0 \\
\hline total & 24 & 373 & 397 \\
\hline
\end{tabular}

Table.5 Occupation ( $p$ value $=0.00$, Pearson Chi-Square Test)

\begin{tabular}{|c|c|c|c|}
\hline \multirow{2}{*}{ Occupation } & \multicolumn{2}{|c|}{ HIV Test Result } & \multirow{2}{*}{ Total (\%) } \\
\cline { 2 - 3 } & Positive (\%) & Negative (\%) & \\
\hline Unemployed & $9(37.5)$ & $25(6.7)$ & $34(8.4)$ \\
\hline Business & 0 & $1(0.3)$ & $1(0.3)$ \\
\hline Farmer & 0 & $48(12.9)$ & $48(12.1)$ \\
\hline Housewife & 0 & $35(9.4)$ & $35(8.8)$ \\
\hline Labourer & $7(21.2)$ & $157(42.1)$ & $164(41.3)$ \\
\hline Shopkeeper & $1(4.2)$ & $36(9.7)$ & $37(9.3)$ \\
\hline Student & 0 & $44(11.8)$ & $44(11.1)$ \\
\hline Tailor & $1(4.2)$ & $25(6.7)$ & $26(6.5)$ \\
\hline Truck driver & $6(25)$ & $2(0.5)$ & $8(2.0)$ \\
\hline Total & 24 & 373 & 397 \\
\hline
\end{tabular}

Table.6 Migration status ( $\mathrm{p}$ value $=0.126$, Pearson Chi-Square Test)

\begin{tabular}{|c|c|c|c|}
\hline \multirow{2}{*}{ Migration status } & \multicolumn{2}{|c|}{ HIV Test result } & \multirow{2}{*}{ Total (\%) } \\
\cline { 2 - 3 } & Positive (\%) & Negative (\%) & \\
\hline Migrant & $12(50)$ & $129(32.5)$ & $141(35.5)$ \\
\hline Non migrant & $12(50)$ & $244(61.5)$ & $256(64.5)$ \\
\hline Total & 24 & 373 & 397 \\
\hline
\end{tabular}

Table.7 Monthly income (p value $=0.392$, Pearson Chi-Square Test)

\begin{tabular}{|c|c|c|c|}
\hline \multirow{2}{*}{ Monthly income } & \multicolumn{2}{|c|}{ HIV Test result } & \multirow{2}{*}{ Total (\%) } \\
\cline { 2 - 3 } & Positive (\%) & Negative (\%) & $95(23.9)$ \\
\hline $0-2500$ & $8(33.3)$ & $87(23.3)$ & $239(60.2)$ \\
\hline $2500-5000$ & $14(58.3)$ & $225(60.3)$ & $63(15.9)$ \\
\hline $5001-7500$ & $2(8.4)$ & $61(16.4)$ & 397 \\
\hline Total & 24 & 373 & \\
\hline
\end{tabular}


Table.8 Marital status ( $\mathrm{p}$ value $=0.00$, Pearson Chi-Square Test)

\begin{tabular}{|c|c|c|c|}
\hline \multirow{2}{*}{ Marital status } & \multicolumn{2}{|c|}{ HIV Test Result } & \multirow{2}{*}{ Total (\%) } \\
\cline { 2 - 3 } & Positive (\%) & Negative (\%) & $83(20.9)$ \\
\hline Unmarried & $7(27.2)$ & $76(20.4)$ & $286(72.0)$ \\
\hline Married & $13(54.2)$ & $273(73.2)$ & $26(6.6)$ \\
\hline Widowed & $2(8.3)$ & $24(6.4)$ & $2(0.5)$ \\
\hline Separated & $2(8.3)$ & 0 & 397 \\
\hline Total & 24 & 373 & \\
\hline
\end{tabular}

Table.9 Sexual behaviour ( $\mathrm{p}$ value $=0.00$, Pearson Chi-Square Test)

\begin{tabular}{|c|c|c|c|}
\hline \multirow{2}{*}{$\begin{array}{c}\text { Who do you have sex } \\
\text { with? }\end{array}$} & \multicolumn{2}{|c|}{ HIV test result } & \multirow{2}{*}{ Total (\%) } \\
\cline { 2 - 3 } & Positive (\%) & Negative (\%) & $46(11.6)$ \\
\hline Only men & 0 & $46(12.3)$ & $7(1.8)$ \\
\hline $\begin{array}{c}\text { Men and women } \\
\text { equally }\end{array}$ & $7(29.2)$ & 0 & $6(1.5)$ \\
\hline Mostly women & 0 & $6(1.6)$ & $338(85.1)$ \\
\hline Only women & $17(70.8)$ & $321(86.1)$ & 397 \\
\hline Total & 24 & 373 & \\
\hline
\end{tabular}

Table.10 Number of sex partners ( $\mathrm{p}$ value $=0.00$, Pearson Chi-Square Test)

\begin{tabular}{|c|c|c|c|}
\hline \multirow{2}{*}{$\begin{array}{c}\text { Number of sexual } \\
\text { partners in last one } \\
\text { year }\end{array}$} & \multicolumn{2}{|c|}{ HIV Test result } & \multirow{2}{*}{ Total (\%) } \\
\cline { 2 - 3 } & Positive (\%) & Negative (\%) & \\
\hline 1 & $3(12.5)$ & 0 & $3(0.8)$ \\
\hline 2 & $12(50)$ & 0 & $12(3.0)$ \\
\hline 3 & $3(12.5)$ & 0 & $3(0.8)$ \\
\hline 4 & $3(12.5)$ & 0 & $3(0.8)$ \\
\hline Declined to answer & $3(12.5)$ & $373(100)$ & $376(94.6)$ \\
\hline Total & 24 & 373 & 397 \\
\hline
\end{tabular}

Table.11 Exposure to CSW ( $\mathrm{p}$ value $=0.00$, Pearson Chi-Square Test)

\begin{tabular}{|c|c|c|c|}
\hline \multirow{2}{*}{$\begin{array}{c}\text { Did you trade sex for } \\
\text { money }\end{array}$} & \multicolumn{2}{|c|}{ HIV Test result } & \multirow{2}{*}{ Total (\%) } \\
\cline { 2 - 3 } & Positive (\%) & Negative (\%) & $14(3.5)$ \\
\hline Yes & $14(58.3)$ & 0 & $383(96.5)$ \\
\hline No & $10(41.7)$ & $373(100)$ & 397 \\
\hline Total & 24 & 373 & \\
\hline
\end{tabular}


Table.12 Anal sex ( $\mathrm{p}$ value $=0.00$, Pearson Chi-Square Test)

\begin{tabular}{|c|c|c|c|}
\hline \multirow{2}{*}{$\begin{array}{c}\text { History of anal } \\
\text { intercourse }\end{array}$} & \multicolumn{2}{|c|}{ HIV test result } & \multirow{2}{*}{ Total (\%) } \\
\cline { 2 - 3 } & Positive (\%) & Negative (\%) & $31(8.9)$ \\
\hline Yes & $17(70.8)$ & $14(4.3)$ & $13(3.7)$ \\
\hline No & $4(16.7)$ & $9(2.8)$ & $306(87.4)$ \\
\hline Declined to answer & $3(12.5)$ & $303(92.9)$ & 350 \\
\hline Total & 24 & 326 & \\
\hline
\end{tabular}

Table.13 Condom use ( $\mathrm{p}$ value $=0.00$, Pearson Chi-Square Test)

\begin{tabular}{|c|c|c|c|}
\hline \multirow{2}{*}{$\begin{array}{c}\text { Penetrative sex } \\
\text { without condom }\end{array}$} & \multicolumn{2}{|c|}{ HIV Test result } & \multirow{2}{*}{ Total (\%) } \\
\cline { 2 - 3 } & Positive (\%) & Negative (\%) & $259(65.2)$ \\
\hline Yes & $24(100)$ & $235(63)$ & $138(34.8)$ \\
\hline No & 0 & $138(37)$ & 397 \\
\hline Total & 24 & 373 & \\
\hline
\end{tabular}

Table.14 Sexually transmitted diseases ( $\mathrm{p}$ value $=0.00$, Pearson Chi-Square Test)

\begin{tabular}{|c|c|c|c|}
\hline \multirow{2}{*}{$\begin{array}{c}\text { History of past or } \\
\text { present STD`s }\end{array}$} & \multicolumn{2}{|c|}{ HIV test result } & \multirow{2}{*}{ Total (\%) } \\
\cline { 2 - 3 } & Positive (\%) & Negative (\%) & $26(6.6)$ \\
\hline Yes & $14(58.3)$ & $12(3.2)$ & $371(93.4)$ \\
\hline No & $10(41.7)$ & $361(96.8)$ & 397 \\
\hline Total & 24 & 373 & \\
\hline
\end{tabular}

Table.15 Alcohol / substance abuse ( $\mathrm{p}$ value $=0.00$, Pearson Chi-Square Test)

\begin{tabular}{|c|c|c|c|}
\hline \multirow{2}{*}{$\begin{array}{c}\text { Use of alcohol / any } \\
\text { other drug }\end{array}$} & \multicolumn{2}{|c|}{ HIV Test result } & \multirow{2}{*}{ Total (\%) } \\
\cline { 2 - 3 } & Positive (\%) & Negative (\%) & $371(93.5)$ \\
\hline Never/no & $6(25)$ & $365(97.9)$ & $15(3.7)$ \\
\hline Sometimes & $7(29.2)$ & $8(2.1)$ & $5(1.3)$ \\
\hline About half a time & $5(20.8)$ & 0 & $6(1.5)$ \\
\hline Almost all the time & $6(25)$ & 0 & 397 \\
\hline Total & 24 & 373 & \\
\hline
\end{tabular}

\section{Sexually Transmitted Diseases}

In the present study, 26(6.5\%) patients gave history of STD. Of these $14(53.8 \%)$ were tested seropositive. Out of 371(93.4\%) patients who did not gave history of any veneral diseases, $10(2.6 \%)$ were seropositive (Table 14). There is significant association between presence of STD and HIV status, which was also reported by Tabot (2012).

\section{Alcohol}

In present study, 6 patients $(25 \%)$ had no history of alcohol or any substance abuse where as 18 patients $(75 \%)$ had history of alcohol intake sometimes to almost all the times (Table 15). None of the patients gave history of injectable drug abuse. History of alcohol/ substance abuse was significantly associated with HIV status, in accordance 
with results reported in other similar studies. In our study, out of 397 patients enrolled, 24 were found to be sero positive. The most important risk behaviours associated with HIV seropositivity were found to be occupation (high in unemployed, labourer, truck drivers), marital status, multiple sex partners, homosexual behavior, condom use, presence of sexually transmitted diseases, visit to commercial sex workers \& use of recreational substances like alcohol before sex. Condom use and substance use risk reduction need to be considered as HIVprevention measures when planning HIVprevention programmes for TB patients. Other parameters which did not show statistical significance, although described as high risk factors in some previous studies, were age and sex, religion, educational status, migration and low socioeconomic status. Possible explanation for this may be the sample size because the studies which have described the socio-economic and demographic association have enrolled hundreds to thousands of respondents from multiple areas/districts. This study supports the fact that sexual behavior and practices are the most important risk factors in transmission of HIV in general population as well as in tuberculosis patients. Improvements are needed in the detection of TB among HIV-positive people, the coverage of HIV testing among TB patients, and the enrolment of HIV-positive TB patients on ART.

\section{Limitations of the Study}

The findings of the study were subject to a few limitations

1. Sample size was small.

2. Only indoor patients were enrolled in this study.

3. Many patients avoided to respond to questions regarding their sexual behavior.

4. Memory recall bias.

\section{References}

Agarwal, S.P., Roy, D., Leuham, L.S. 2005. HIV-TB coinfection: A lethal combination. Tuberculosis in India New Delhi. Director general of Health Services, Ministery of Health and Family Welfare, Govt. of India, pp.145154.

Dandona, L., Dandona, R., Kumar, G.A., Reddy, G.B., Ameer, M.A., Ahmed, G.M., et al. 2008. Risk factors associated with HIV in a populationbased study in Andhra Pradesh state of India, Int. J. Epidemiol., 37: 12741286.

Global Tuberculosis Report, World Health Organisation. 2016. http://apps.who.int/iris/bitstream/10665/ 250441/1/9789241565394-

eng.pdf?ua $=1$

HIV Factsheet 2016. World Health Organisation.

http://www.who.int/mediacentre/factshe ets/fs360/en/

HIV risk behavior among public PHC patients with TB in South Africa. 2013. S Afr. J. HIV Med., 14(3): 125-130.

Jain, S.K., Aggarwal, J.K., Rajpal, S., Baveja, U. 2000. Prevalence of HIV infection among tuberculosis patients in Delhi - a sentinel surveillance study. Ind. J. Tub., 47: 21.

Maher, D., Floyd, K., Raviglione, M. 2002. Strategic framework to reduce the burden of TB/HIV. Geneva, World Health Organization, (WHO/CDC/ TB/2002.296).

Oladeinde, et al. 2014. HIV-TB co-infection in rural Nigeria, Nigerian $J$. Experimental and Clin. Biosci., 2(2): 90-94.

Pandey, A., et al.2008. Risk behavior, sexually transmitted infections and HIV among long-distance truck drivers: a 
cross-sectional survey along national highways in India'. AIDS, 22(5): 81-90.

Pawlowski, A., Jansson, M., Skold, M., Rottenberg, M.E., Kallenius, G. 2012. Tuberculosis and HIV Co-Infection. PLoS Pathog., 8: e1002464.

Ramachandran, R., Chandrasekaran, V., Muniyandi, M., Jaggarajamma, K., Bagchi, A., Sahu, S. Prevalence and Risk Factors of HIV Infection among Clients Attending ICTCs in Six Districts of Tamilnadu, South India. AIDS Res. Treatment, 10-17.

Srikantiah, P., Lin, R., Walusimbi, M., Okwera, A., Luzze, H., Whalen, C.C., W.H. Boom, W.H., et al. 2007. Elevated HIV seroprevalence and risk behavior among Ugandan TB suspects: implications for HIV testing and prevention. Int. J. Tuberc. Lung Dis., 11(2): 168-174.

Talbot, E.A., Kenyon, T.A., Moeti, T.L., Hsin, G., Dooley, L. 2002. HIV risk factors among patients with tuberculosis - Botswana 1999. Int. J. STD \& AIDS, 13: 311-317.
Talzek, E.E. 1997. Tuberculosis and Human immunodeficiency Virus infection. Med. Clin. North Am., 81(2): 345-360.

TB-HIV Factsheet 2016. World Health Organisation. http://www.who.int/tb/areas-of-work/tbhiv/tbhiv_factsheet_2016_web.pdf?ua= 1

Thomas, B.E., S. Chandra, K.J.A. Selvi, D. Suriyanarayanan \& Soumya Swaminathan. 2009. Gender differences in sexual behavior among people living with HIV in Chennai, India. Indian J. Med. Res., 129: 690-694.

World Health Organization. 2002. Strategic framework to decrease the burden of TB/HIV. Geneva, World Health Organziaton, WHO/CDS/TB/2002.296; WHO/HIV_AIDS/2002.2.

Xu, J., Tang, W., Cheng, S., Mahapatra, T., Zhou, L., Lai, Y., et al. 2014. Prevalence and Predictors of HIV among Chinese Tuberculosis Patients by Provider-Initiated HIV Testing and Counselling (PITC): A Multisite Study in South Central of China. PLoS One, 9: e89723.

\section{How to cite this article:}

Ankur Gupta, Priyanka Soni Gupta and Rakesh Chandra Gupta. 2017. Study of the Prevalence of Risk Behaviour for HIV among Tuberculosis Patients. Int.J.Curr.Microbiol.App.Sci. 6(5): 505-515. doi: https://doi.org/10.20546/ijcmas.2017.605.059 